\title{
Prehospital 12-lead electrocardiogram for patients with chest pain: a pilot study
}

\author{
KS Cheung *, LP Leung, YC Siu, TC Tsang, Matthew SH Tsui, CC Tam, Raymond HW Chan
}

\section{A B S T R A C T}

Introduction: After ST-segment elevation myocardial infarction (STEMI), it is vital to shorten reperfusion time. This study examined data from a pilot project to shorten the door-to-balloon (D2B) time by using prehospital 12-lead electrocardiogram (ECG).

Methods: Fifteen ambulances equipped with X Series ${ }^{\circledR}$ Monitor/Defibrillator (Zoll Medical Corporation) were deployed to the catchment area of Queen Mary Hospital, Hong Kong, from November 2015 to December 2016. For patients with chest pain, prehospital 12-lead ECG was performed and tele-transmitted to attending physicians at the accident and emergency department for immediate interpretation. The on-call cardiologist was called before patient arrival if STEMI was suspected. Data from this group of patients with STEMI were compared with data from patients with STEMI who were transported by ambulances without prehospital ECG or by self-arranged transport.

Results: From 841 patients with chest pain, 731 gave verbal consent and prehospital ECG was performed and transmitted. Of these, 25 patients with clinically diagnosed STEMI required emergency coronary angiogram with or without primary percutaneous coronary intervention. The mean D2B time for these 25 patients (93 minutes) was significantly shorter

This article was published on 28 Sep 2018 at www.hkmj.org. $(\mathrm{P}=0.003)$ than that for 58 patients with STEMI

ECG (112 minutes) and that for 41 patients with STEMI with self-arranged transport (138 minutes). However, shorter reperfusion time was only recorded during daytime hours (08:00-17:59). No statistically significant difference in 30-day mortality was found.

Conclusion: Prehospital ECG is technologically feasible in Hong Kong and shortens the D2B time. However, shorter reperfusion time was only recorded during daytime hours.

\author{
Hong Kong Med J 2018;24:484-91 \\ DOI: $10.12809 / \mathrm{hkmj} 177135$
KS Cheung *, FHKCEM, MSc Cardiology
${ }^{2}$ LP Leung, FHKCEM
${ }^{3}$ YC Siu, FHKCEM
${ }^{1}$ TC Tsang, FHKCEM
${ }^{1}$ MSH Tsui, FRCP (Edin), FHKAM (Emergency Medicine)
${ }^{4}$ CC Tam, FHKCP, FHKAM (Medicine) \\ ${ }^{5}$ RHW Chan, FHKAM (Medicine)
}

\section{Department of Accident and Emergency, Queen Mary Hospital, Pokfulam, Hong Kong \\ Emergency Medicine Unit, Li Ka Shing Faculty of Medicine, The University of Hong Kong, Pokfulam, Hong Kong \\ ${ }^{3}$ Medical Director, Fire and Ambulance Services Academy, Hong Kong Fire Services Department, Hong Kong \\ ${ }^{4}$ Department of Medicine, Queen Mary Hospital, Pokfulam, Hong Kong \\ ${ }^{5}$ Honorary Consultant Cardiologist, Hong Kong Sanatorium Hospital, Happy Valley, Hong Kong}

*Corresponding author: cks373@ha.org.hk

New knowledge added by this study

- This pilot study investigated the feasibility and performance of prehospital 12-lead electrocardiogram (ECG) deployed in ambulances in Hong Kong.

- There was a statistically significant difference in door-to-balloon time when prehospital ECG was performed during daytime hours.

- There was no statistically significant difference in 30-day mortality related to the use of prehospital ECG.

Implications for clinical practice or policy

- Based on the evidence of feasibility and shortening of door-to-balloon time in Hong Kong, prehospital ECG services might be supported by the Hong Kong Fire Services Department.

- Primary diversion of ST-elevation myocardial infarction may be implemented in Hong Kong in the future.

\section{Introduction}

In 1970, Nagel et $\mathrm{al}^{1}$ first reported the transmission of single-lead electrocardiogram (ECG) data via radio system to hospital physicians in Florida, US, for diagnostic purposes. To date, prehospital 12-lead ECG programmes have been implemented in various countries. In 2015, the American Heart Association
Guidelines for Cardiopulmonary Resuscitation and Emergency Cardiovascular Care recommended that prehospital 12-lead ECG should be acquired early for patients with possible acute coronary syndrome. ${ }^{2}$ The acquisition and tele-transmission of ECG data to the accident and emergency department (AED) allows rapid diagnosis of ST-segment elevation myocardial 
infarction (STEMI) by attending physicians. The on-call cardiologist and cardiac catheterisation laboratory (CCL) can then be notified early. This significantly shortens the door-to-balloon (D2B) time and improves patient outcome. ${ }^{3}$

The Hong Kong Fire Services Department (HKFSD) is the major emergency ambulance service provider in Hong Kong. Ambulances are deployed by the Fire Service Control Centre after calls to 999 and are manned by ambulance crew in accordance with pre-set protocols approved by the Medical Director of the HKFSD. Patients are transported to the nearest public hospital based on their geographical location. There is no choice with respect to the destination hospital, and there was no primary diversion for chest pain or STEMI in the project period.

Queen Mary Hospital (QMH) is a tertiary care hospital providing 24-hour emergency medical services in Hong Kong. Since November 2010, QMH has been the only public hospital in Hong Kong providing a 24-hour primary percutaneous coronary intervention (PPCI) service for all patients with STEMI.

In November 2015, the HKFSD and the QMH AED jointly launched a pilot project named 'Prehospital Ambulance 12-Lead Electrocardiogram for Chest Pain Patients in Hong Kong West Cluster'. The present paper reports on the results of the first phase of that project. We hypothesised that prehospital ECG would shorten the D2B time and reduce mortality in patients with STEMI treated in AEDs in Hong Kong.

\section{Methods}

The present retrospective observational study analysed data from the 'Prehospital Ambulance 12-Lead Electrocardiogram for Chest Pain Patients in Hong Kong West Cluster' pilot project. That project began on 12 November 2015 and its first phase ended on 31 December 2016. All 122 ambulance crew members involved with the study received a half-day theory and hands-on training by clinical specialists of Zoll Medical Corporation (Chelmsford [MA], US) regarding the performance of prehospital 12-lead ECG. During the project period, there were 20 HKFSD ambulances operating in the catchment area of QMH; 10 were not operated during the night shift. Of these 20 ambulances, 15 were equipped with X Series ${ }^{\circledR}$ Monitor/Defibrillator (Zoll Medical Corporation) with ECG and tele-transmission functions. These 15 ambulances were deployed by the HKFSD to Aberdeen Ambulance Depot, Pok Fu Lam Ambulance Depot, Mount Davis Ambulance Depot, and Sheung Wan Fire Station.

In addition to the conventional management of chest pain or discomfort of cardiac origin, ambulance crews performed prehospital ECG (Fig). The ambulance crews were trained to use

\section{為胸痛病人進行院前 12 導心電圖之先導研究} 張健碩、梁令邦、蕭粵中、曾達之、徐錫漢、譚礎璋、陳漢鏵 引言：罹患ST上升心肌梗塞（STEMI），縮短再灌注時間是很重要 的。本研究檢視一項以院前 12 導心電圖縮短到院至灌流時間的先導計 劃中的數據。

方法：2015年11月至2016年12月期間, 在 15 部瑪麗醫院服務範圍內 的救護車上配置了X系列去顫器 / 監護儀, 為胸痛病人進行院前 12 導 心電圖並傳送到急症室供醫生即時分析。如心電圖顯示有STEMI, 在病人抵達急症室前已可聯絡當值的心臟科醫生。本研究比較三組 STEMI病人的數據, 分別為參加此先導計劃、乘坐救護車而沒有進行 院前心電圖，以及自行安排交通工具前往醫院的病人。

結果：841名胸痛病人當中, 731名病人同意並成功接受及傳送院前心 電圖。當中, 25 名確診STEMI的病人接受緊急心導管檢查或附以介入 治療; 他們由到院至灌流時間平均需時93分鐘, 較乘坐沒有進行院前 心電圖救護車的58名STEMI病人（112分鐘）以及自行安排交通工具 的41名STEMI病人（138分鐘）為快（ $\mathrm{P}=0.003 ）$ 。不過, 較短再灌 流時間只限於日間登記的病人（08:00-17:59）。30日內之死亡率亦 未見明顯分別。

結論：在香港, 院前心電圖在技術上可行, 並能縮短到院至灌流時 間。然而, 本研究顯示再灌流時間縮短只限於日間求診病人。

a standardised script in Chinese or English to explain the indication, procedure, benefit, and risk of performing prehospital ECG. Patients and accompanying relatives were provided with sufficient time for questions before informed consent was obtained. Patients were excluded if they were under 12 years of age; were in cardiac arrest; exhibited airway or breathing that could not be managed; had Glasgow Coma score $\leq 13$; had first systolic blood pressure $<90 \mathrm{~mm} \mathrm{Hg}$; had respiratory rate $<10$ or $>29$ breaths per minute; or were otherwise unable to consent.

The prehospital ECG was obtained in the ambulance compartment before its departure from the scene and was immediately tele-transmitted to the AED for interpretation by a physician. When a new prehospital ECG was transmitted, staff at the AED were notified via a dedicated laptop with alarm, fax, and email, as well as an alert phone call from the ambulance crew en route. The patient's Hong Kong Identity Card number was also conveyed through the alert phone call from the ambulance. This allowed early identification of any new changes in the prehospital ECG, compared with previous ECG data stored in the hospital clinical management system record.

The most senior attending AED physician 
available was responsible for reading and interpreting the prehospital ECG. If the AED physician identified ST-segment elevation in two or more contiguous leads, the on-call cardiologist was paged and AED manpower and equipment were arranged immediately. Patients without such ST-segment elevation were triaged by experienced AED nurses upon arrival, in accordance with their overall clinical condition.

To compare the characteristics and outcomes of patients in this pilot project with those of other patients with chest pain (ie, those attending the AED by ambulance without prehospital ECG, or by self-arranged transport), data from the cardiac care unit of QMH were collected for comparison. Data

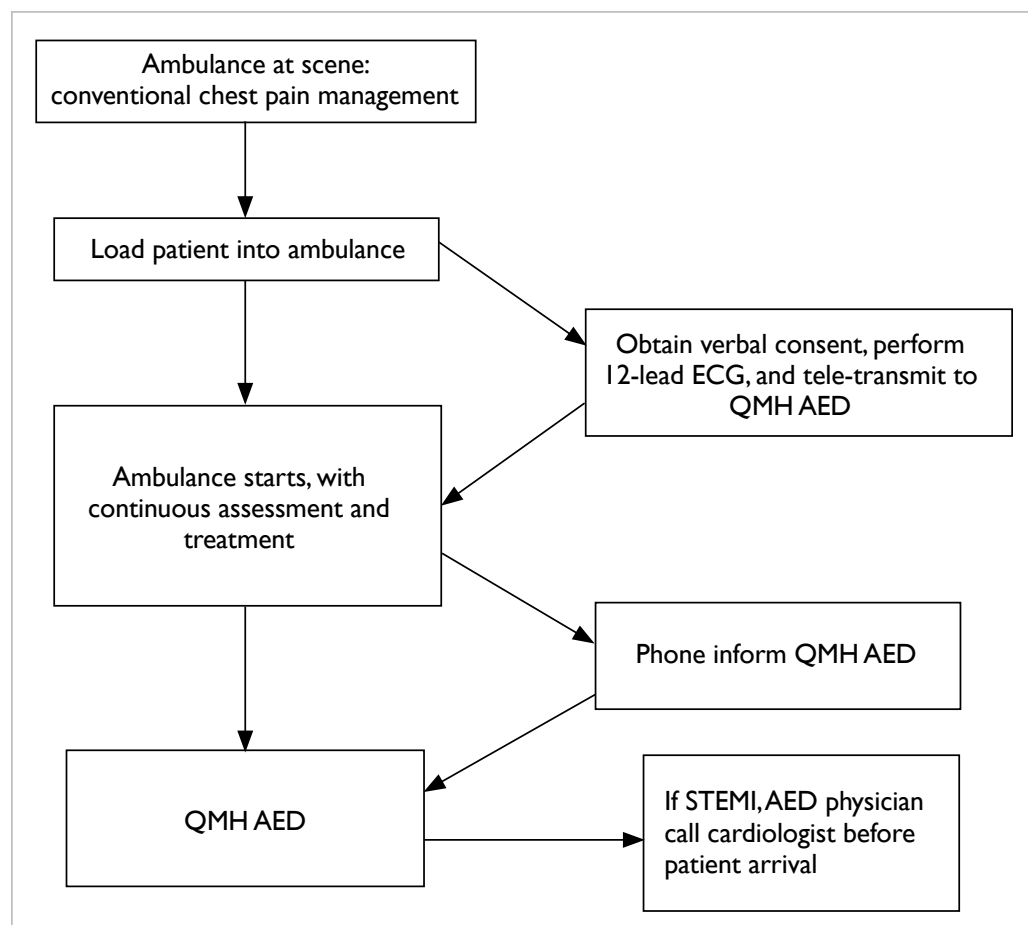

FIG. Flowchart of prehospital ECG performance

Abbreviations: $\mathrm{AED}=$ accident and emergency department; $\mathrm{ECG}=$

electrocardiogram; STEMI = ST-segment elevation myocardial infarction; $\mathrm{QMH}=$ Queen Mary Hospital of all patients attending the AED with emergency coronary angiography, with or without PPCI, were analysed. The D2B or door-to-catheter (D2C) time of different subgroups was determined and analysed as the primary outcome of this study. Secondary outcomes, including performance in daytime or night-time AED registration, triage accuracy, and 30-day mortality, were assessed in further subgroup analysis.

\section{Results}

From 12 November 2015 to 31 December 2016, ambulance crews equipped with X Series ${ }^{\circledR}$ attended to 841 patients presenting with cardiac chest pain. Verbal consent to perform prehospital ECG was obtained from 731 (86.9\%) patients and these were included for analysis. A mean 1.76 prehospital ECGs were successfully performed and transmitted per day during the pilot project period. Reasons for not performing prehospital ECG are shown in Table 1.

In total, $60 \%$ of patients were male. The patients' mean age was 71 years, with a difference of 10 years between male (mean, 67 years) and female (mean, 77 years) patients. More patients registered at the AED during daytime hours (08:00-17:59; $\mathrm{n}=380$ [52.0\%]) than during night-time hours (18:00-07:59; $\mathrm{n}=351$ [48.0\%]). Most patients were triaged as category 3 in the AED $(n=577)$ [78.9\%]; those triaged as category 1 (critical), 2 (emergency), 4 (semi-urgent), and 5 (non-urgent) were 39 (5.3\%), 57 (7.8\%), 58 (7.9\%), and 0 , respectively.

In all, 93\% of cases with cardiac chest pain were managed by AED physicians without further on-site consultation. Consultations with physicians from the cardiac care unit were initiated by the AED physician for 53 patients: 22 (41.5\%) were performed on or before patient arrival at the AED, whereas the remaining 31 (58.5\%) were conducted after patient arrival.

Of the 731 patients who received pre-hospital ECG, 534 (73.1\%) patients were admitted to the medical ward, $96(13.1 \%)$ to the emergency medical ward, $33(4.5 \%)$ to the cardiac care unit, $13(1.8 \%)$ to the surgical ward, three $(0.4 \%)$ to the intensive care unit, and one $(0.1 \%)$ to the neurosurgical ward for further management of their symptoms. Of

TABLE I. Reasons for lack of consent for prehospital ECG in the ambulance $(n=110)$

\begin{tabular}{lc}
\hline Reason & No. \\
\hline Patient was unwilling to undergo 12-lead ECG, acquired by ambulance crew & 73 \\
Patient expected rapid transport to Queen Mary Hospital and did not want to waste time & 25 \\
Patient was unfamiliar with 12-lead ECG & 7 \\
\hline Patient was uncomfortable with 12-lead ECG inside the ambulance compartment due to privacy & 5 \\
\hline
\end{tabular}

Abbreviation: ECG = electrocardiogram 
the remaining patients, 39 (5.3\%) were discharged 25 patients with STEMI treated with prehospital from the AED, eight (1.1\%) were discharged against ECGs; 58 patients with STEMI who were treated by medical advice, three $(0.4 \%)$ disappeared, and one (0.1\%) was certified in the AED.

ambulance crews without prehospital ECGs; and 41 self-transported patients with STEMI treated in the

Of the 731 patients who received pre-hospital QMH AED during the pilot project period (Table 2). ECG, 26 (3.6\%) patients were clinically diagnosed A statistically significant difference was found in the with STEMI by AED physicians. Coronary mean D2B time $(\mathrm{P}=0.003)$. Patients with prehospital angiogram, with or without PPCI, was arranged ECGs had the shortest mean D2B (93 minutes) and immediately for 25 of these patients. The remaining D2C (71 minutes) times. Additionally, a greater patient had a terminal malignancy and was offered percentage of patients with prehospital 12-lead ECG non-invasive treatment after discussion with the had D2B or D2C time $\leq 90$ minutes.

patient's family.

Table 3 shows that there were significant

The mean D2B and D2C times were compared differences in D2B or D2C times among the three among 124 patients with clinically diagnosed STEMI: groups of patients with STEMI attending the AED

TABLE 2. D2B and D2C times for patients in the ambulance (with and without prehospital ECG) and self-arranged transport groups ( $n=124)$

\begin{tabular}{|c|c|c|c|}
\hline & $\begin{array}{l}\text { Ambulance with } \\
\text { prehospital ECG }(n=25)\end{array}$ & $\begin{array}{l}\text { Ambulance without } \\
\text { prehospital ECG }(n=58)\end{array}$ & $\begin{array}{l}\text { Self-arranged transport } \\
\qquad(n=41)\end{array}$ \\
\hline \multicolumn{4}{|c|}{$\begin{array}{l}\text { Patients with STEMI + coro + PPCI (range, 41-369 min), } \\
\mathrm{n}=107\end{array}$} \\
\hline D2B time, min, mean $(95 \% \mathrm{Cl})$ & $93(74.39-111.61)[n=22]$ & $112(100.96-124.13)[n=48]$ & $138(116.99-158.74)[n=37]$ \\
\hline$\leq 90 \mathrm{Min}$ & $13(59 \%)$ & $17(35 \%)$ & $6(16 \%)$ \\
\hline$>90 \mathrm{Min}$ & $9(41 \%)$ & $31(65 \%)$ & $31(84 \%)$ \\
\hline$P$ value* & 0.003 & & \\
\hline Post-hoc $\mathrm{P}$ value $†$ & Not applicable & 0.380 & 0.003 \\
\hline \multicolumn{4}{|c|}{ Patients with STEMI + coro (range, 31-295 min), n=17 } \\
\hline D2C time, min, mean $(95 \% \mathrm{Cl})$ & $71(-28.04$ to 170.71$)[n=3]$ & $145(103.13-185.87)[n=10]$ & $127(69.67-183.83)[n=4]$ \\
\hline$\leq 90 \mathrm{Min}$ & $2(67 \%)$ & 0 & 0 \\
\hline$>90$ Min & $1(33 \%)$ & $10(100 \%)$ & $4(100 \%)$ \\
\hline$P$ value ${ }^{*}$ & 0.134 & & \\
\hline Post-hoc $\mathrm{P}$ value $\dagger$ & Not applicable & 0.147 & 0.543 \\
\hline
\end{tabular}

Abbreviations: $\mathrm{Cl}$ = confidence interval; coro = coronary angiogram; D2B = door-to-balloon; D2C = door-to-catheter; ECG = electrocardiogram; PPCI = primary percutaneous coronary intervention; STEMI = ST-segment elevation myocardial infarction

* F-test used for analysis of variance

† $\mathrm{P}$ value of post-hoc $t$ tests with Bonferroni correction, compared with ambulance patients with prehospital ECG

TABLE 3. Daytime and night-time D2B or D2C times for patients in the ambulance (with and without prehospital ECG) and self-arranged transport groups $(n=124)$

\begin{tabular}{|c|c|c|c|}
\hline & $\begin{array}{l}\text { Ambulance with prehospital } \\
\text { ECG }(n=25)\end{array}$ & $\begin{array}{l}\text { Ambulance without } \\
\text { prehospital ECG }(n=58)\end{array}$ & $\begin{array}{l}\text { Self-arranged transport } \\
\qquad(n=41)\end{array}$ \\
\hline \multicolumn{4}{|l|}{ Daytime hours (08:00-17:59), n=76 } \\
\hline D2B or D2C time, min, mean $(95 \% \mathrm{Cl})$ & $74(58.24-90.00)[n=17]$ & $113(94.70-131.36)[n=33]$ & $130(104.48-156.44)[n=26]$ \\
\hline$P$ value* & 0.004 & & \\
\hline Post-hoc $\mathrm{P}$ value $†$ & Not applicable & 0.048 & 0.003 \\
\hline \multicolumn{4}{|l|}{ Night-time hours (18:00-07:59), $\mathrm{n}=48$} \\
\hline D2B or D2C time, min, mean $(95 \% \mathrm{Cl})$ & $125(90.26-159.74)[n=8]$ & $125(111.12-138.24)[n=25]$ & $148(118.47-176.99)[n=15]$ \\
\hline$P$ value* & 0.215 & & \\
\hline Post-hoc $\mathrm{P}$ value $\dagger$ & Not applicable & 1.0 & 0.648 \\
\hline
\end{tabular}

Abbreviations: $\mathrm{Cl}=$ confidence interval; D2B = door-to-balloon; D2C = door-to-catheter; $\mathrm{ECG}=$ electrocardiogram

* F-test used for analysis of variance

† $P$ value of post-hoc $t$ tests with Bonferroni correction, compared with ambulance patients with prehospital ECG 
during daytime hours (08:00-17:59); there were no significant differences between the groups during night-time hours. The overall 30-day mortality of all patients with clinically diagnosed STEMI was 8\% (10 of 124 patients) [Table 4]. Fisher's exact test did not demonstrate any statistically significant difference between the intervention and control groups.

When clinical diagnoses of STEMI were used as a standard to verify diagnoses made by the $\mathrm{X}$ Series ${ }^{\circledR}$ Monitor/Defibrillator diagnostic algorithm, there were 14 true positive, three false positive, 702 true negative, and 12 false negative cases. This corresponded to sensitivity $(53.8 \%)$, specificity (99.6\%), positive predictive value $(82.4 \%)$, negative predictive value (98.3\%), and accuracy (97.9\%).

\section{Discussion}

\section{Clinical diagnosis of ST-segment elevation myocardial infarction}

In an AED without point-of-care cardiac biomarker testing capability, it is impossible to immediately detect a rise and/or fall in cardiac biomarkers, as described in the 'Fourth universal definition of myocardial infarction." Some patients in the AED with chest discomfort or other ischaemic symptoms, who developed ST elevation in two contiguous leads, were clinically diagnosed with STEMI before confirmation of typical biomarker changes, resulting in corresponding modification to medical management. This caused inaccuracy in calculation of the diagnostic performance of the diagnostic algorithm used in the X Series ${ }^{\circledR}$, when the clinical diagnosis of STEMI in the AED was used as a standard for comparison.

\section{Shortened door-to-balloon or door-to- catheter time during daytime hours}

The theoretical benefits of prehospital 12-lead
ECG included early diagnosis by AED physicians, early activation of the Acute Myocardial Infarction Clinical Pathway with cardiologist input, and activation of the CCL. It worked well during office hours, when the full team of interventional cardiologists, cardiac care nurses, and radiographers were on-site. The shortest D2B time was 41 minutes. However, during non-office hours or night-time hours, this team had to return from their homes for PPCI. This was the time-limiting factor during night-time hours and there was no statistically significant difference in night-time D2B or D2C time in our series for ambulance patients with or without prehospital 12-lead ECG. Possible solutions might be the provision of sufficient manpower for a 24-hour on-site interventional cardiology team. Other measures, such as cardiologists receiving prehospital 12-lead ECG data through their mobile phones, or activation of the CCL by emergency physicians (with an increased risk of inappropriate activation) could be considered.

\section{Comparison with international standards for reperfusion}

A greater percentage of patients with STEMI with prehospital 12-lead ECGs received reperfusion therapy with PPCI $\leq 90$ minutes (Table 2). There was also a reduction in 30 -day mortality to $0 \%$ in this subgroup (Table 4). However, whether a causeand-effect relationship existed is uncertain, due to our small sample size. Additionally, a statistically significant difference in 30-day mortality could not be demonstrated in our pilot project. Other cardiovascular outcome measurements, including re-infarction rate, major adverse cardiac events, and heart failure rate could be studied to provide insights regarding the benefit of prehospital 12-lead ECGs.

The $\mathrm{D} 2 \mathrm{~B}$ or $\mathrm{D} 2 \mathrm{C}$ time could be improved through measures such as the performance of

TABLE 4. Thirty-day mortality of patients admitted to the cardiac care unit from the accident and emergency department with emergency coronary angiogram with or without $\mathrm{PPCl}$

\begin{tabular}{|c|c|c|c|c|}
\hline & \multirow{2}{*}{$\begin{array}{c}\text { Intervention }(n=25)^{\star} \\
\text { Ambulance with } \\
\text { prehospital 12-lead ECG } \\
(n=25)\end{array}$} & \multicolumn{3}{|c|}{ Control $(n=99)^{*}$} \\
\hline & & $\begin{array}{l}\text { Ambulance without } \\
\text { prehospital 12-lead ECG } \\
(n=58)\end{array}$ & $\begin{array}{l}\text { Self-arranged transport } \\
\qquad(n=41)\end{array}$ & Subtotal $(n=99)$ \\
\hline \multicolumn{5}{|l|}{$\begin{array}{l}\text { Patients with STEMI + coro + } \\
\text { PPCI, } n=107\end{array}$} \\
\hline 30-Day mortality, No. (95\% Cl) & $0 / 22,0-18.5 \%$ & 5/48 (10.4\%), 3.9\%-23.4\% & 2/37 (5.4\%), 0.9\%-19.5\% & $7 / 85$ (8.2\%), 3.7\%-16.8\% \\
\hline \multicolumn{5}{|l|}{ Patients with STEMI + coro, $\mathrm{n}=17$} \\
\hline 30-Day mortality, No. (95\% Cl) & 1/3 (33.3\%), 1.8\%-87.5\% & 2/10 (20\%), 3.5\%-55.8\% & $0 / 4,0-60.4 \%$ & 2/14 (14.3\%), 2.5\%-43.8\% \\
\hline \multicolumn{5}{|c|}{ Total: 10/124 (8\%), 4.2\%-14.7\% } \\
\hline
\end{tabular}

Abbreviations: $\mathrm{Cl}=$ confidence interval; coro = coronary angiogram; ECG = electrocardiogram; PPCl = primary percutaneous coronary intervention;

STEMI = ST-segment elevation myocardial infarction

* $P=0.340$ by Fisher's exact test for mortality between intervention and control groups in STEMI + coro + PPCl 
prehospital 12-lead ECGs on scene (rather than in-ambulance), or skipping AED consultation with direct cardiac care unit admission for patients suspected of STEMI on prehospital ECGs. ${ }^{5}$

\section{Inappropriate activation and false positivity}

Inappropriate activation of the CCL occurred when the interventional cardiologist provided an alternative diagnosis or considered the patient not to be a candidate for PPCI, with subsequent cancellation of the catheterisation procedure. In $\mathrm{QMH}$, the CCL was activated by the on-call cardiologist, not the emergency physician, for appropriate patients with STEMI after on-site assessment. Therefore, inappropriate activation of the CCL by the emergency physician was $0 \%$ in our series. Instead, false positivity existed. False positivity was defined as patients with absence of thrombus causing obstruction in the culprit vessels and absence of a typical rise and fall of cardiac enzymes. In our pilot project, 17 of 124 patients with STEMI admitted through the AED had an emergency coronary angiogram performed without PPCI. Excluding one patient with triple vessel occlusion who failed PPCI and required emergent coronary artery bypass grafting, this yielded a false positive rate of $12.9 \%$ (16 of 124 patients). Prehospital 12-lead ECG extended the emergency assessment of patient condition to the prehospital phase. This allowed comparison of prehospital and AED ECGs. Dynamic ECG changes that occurred during the ambulance journey were more likely to be detected. Whether this might help to reduce the false positive activation of CCL or false negative discharge of patients from AED can be studied in the future.

\section{Immediate electrocardiogram interpretation}

In our pilot project, all ambulances equipped with X Series ${ }^{\circledR}$ Monitor/Defibrillator served the QMH catchment area without primary diversion. If primary diversion of patients with STEMI to a hospital with 24-hour PPCI service were to be implemented, on-scene ECG interpretation should be highly sensitive to avoid under-diversion. The ECG data could be interpreted by ambulance crews, machine diagnostic algorithm, or emergency physicians or cardiologists through tele-transmission. However, not all ambulance crews in Hong Kong are trained to interpret ECG data. Additionally, when compared with clinical diagnosis of STEMI in the AED, the sensitivity of the diagnostic algorithm used was $53.8 \%$ in our pilot project. Given this moderate sensitivity, immediate ECG interpretation by experienced emergency physicians or cardiologists is preferable. This diagnostic process is inevitably time-consuming. If ECG were performed on-scene instead of in the ambulance compartment, transport of the patient from scene to ambulance and the diagnostic process could happen simultaneously. Before ambulance departure from the scene, input from the emergency physician or cardiologist would be readily available to guide appropriate destination AED selection.

\section{Reduction of under-triage in accident and emergency department}

Triage by AED nurses must be both efficient and accurate, especially during busy periods. However, chest pain is a subjective perception, as are all types of pain. Before the availability of ECG, the vital signs and brief clinical contact between triage nurses and patients determined the assigned triage category for each patient. Because patients with STEMI belonged to category 1 (critical), it is inevitable that there would be increased under-triage of STEMI cases in the control group (Table 5). Prehospital ECG allowed more accurate triage of patients with STEMI.

\section{Overestimation of daytime door-to-balloon or door-to-catheter time}

In total, $61.3 \%(76 / 124)$ [Table 3] of emergency

TABLE 5. Distribution of triage categories in all STEMI cases*

\begin{tabular}{|c|c|c|c|}
\hline \multirow[t]{2}{*}{ Triage category } & \multirow{2}{*}{$\begin{array}{c}\text { Intervention }(\mathrm{n}=\mathbf{2 5}) \\
\text { Ambulance with prehospital } \\
\text { ECG }(n=25)\end{array}$} & \multicolumn{2}{|c|}{ Control $(n=99)$} \\
\hline & & $\begin{array}{c}\text { Ambulance without } \\
\text { prehospital ECG }(n=58)\end{array}$ & $\begin{array}{l}\text { Self-transport } \\
\qquad(\mathrm{n}=41)\end{array}$ \\
\hline 1 & 23 & 32 & 26 \\
\hline 2 & 1 & 12 & 0 \\
\hline 3 & 1 & 13 & 11 \\
\hline 4 & 0 & 1 & 4 \\
\hline 5 & 0 & 0 & 0 \\
\hline Correctly triaged as category 1 & $23 / 25,92.0 \%$ & \multicolumn{2}{|c|}{$58 / 99,58.6 \%$} \\
\hline
\end{tabular}

Abbreviations: ECG = electrocardiogram; STEMI = ST-segment elevation myocardial infarction

* $P<0.00$ I by Fisher's exact test, when the intervention group was compared with two control groups 
coronary angiograms with or without PPCI were performed during daytime hours (08:00-17:59). However, this total includes patients who registered during non-office hours on Saturday, Sunday, and public holidays; during some of these, activation of the CCL involved the interventional cardiology team returning from home, as would be necessary during night-time hours. Because night-time D2B or D2C times were consistently longer than those recorded during daytime hours (Table 3), daytime D2B or D2C times were most likely overestimated. Studies have shown that in units with no significant difference in reperfusion time during daytime and night-time hours, the mortality of patients with STEMI was not influenced by whether patients presented during standard working hours or outside of these hours. ${ }^{6}$ Measures could be implemented to shorten the night-time D2B or D2C time for improved patient outcomes.

\section{Thirty-day mortality}

The Acute Myocardial Infarction Clinical Pathway was first established in QMH in 2007; by 2011, it successfully reduced the 30-day mortality rate of acute myocardial infarction from $18.4 \%$ to $14.9 \%{ }^{7}$ The mortality in our pilot project was $8.2 \%$ in the control group with conventional management (Table 4). This reduction of mortality in the control group was likely a combined result of advances in cardiovascular medications and diagnostic or therapeutic technologies, as well as improvement of patient health awareness in recent years. With implementation of prehospital 12-lead ECG, further reduction of mortality was expected. In our subgroup with prehospital 12-lead ECG and PPCI, 30 -day mortality of $0 \%$ was recorded. However, a larger study over longer period of time is needed to establish whether there is a statistically significant clinical impact of prehospital 12-lead ECG on longterm mortality.

\section{Mode of transport}

Approximately one-third (41 of 124) of patients with AED diagnosis of STEMI arranged self-transport, rather than calling an ambulance. This underuse of the ambulance service is not unique to Hong Kong $^{8-10}$ and has been a well-documented cause of delayed hospital presentation ${ }^{8,10}$ and reperfusion time. $^{10}$ In addition to the inability to perform prehospital ECG, patients with STEMI who selftransported to the AED were deprived of early assessment by the ambulance crew, administration of aspirin and/or sublingual nitrate, early notification of the AED for patients with unstable vitals, and immediate cardiopulmonary resuscitation (with defibrillation if necessary). Thus, wise use of the ambulance service should be advocated.

\section{Incomplete coverage of the catchment area}

According to the HKFSD, 88\% of the QMH catchment area was covered by the 15 ambulances with $\mathrm{X}$ Series ${ }^{\circledR}$ Monitor/Defibrillator installed. Owing to this incomplete catchment area coverage, 48 ambulance patients did not receive prehospital ECG before PPCI. A greater benefit might be observed in the future, if all ambulances in the territory were capable of transmitting prehospital ECG, together with primary diversion of patients with STEMI.

\section{Patient refusal}

Consent to perform prehospital 12-lead ECG was not obtained from 110 of 841 (13.1\%) patients with cardiac chest pain (71 female and 39 male patients). Refusal to consent may result in worse outcomes for patients with STEMI with delayed PPCI. Public education regarding the benefit of performing prehospital ECG may reduce refusal rates.

\section{Referral from private physicians}

Of 124 patients with STEMI attending the AED, $20(16.1 \%)$ consulted private physicians before attendance to the AED; a number of ECGs performed in these private clinics or hospitals documented STEMI. However, apart from handwritten referral letters, there is currently no formal direct communication channel between private physicians and AED physicians. More convenient means of prehospital communication with or without teletransmission of prehospital 12-lead ECG performed in private clinics or hospitals could be explored. The benefits of seamless communication between private physicians and the AED are not limited to STEMI alone and may affect many other medical conditions.

\section{Conclusion}

Prehospital 12-lead ECG is technologically feasible in Hong Kong and shortens the D2B time. However, shorter reperfusion time was recorded only during daytime hours. Promotion of prehospital 12-lead ECG and proper utilisation of ambulance services for patients with cardiac chest pain may allow additional patients with STEMI to benefit from prehospital ECG.

\section{Author contributions}

Concept or design: All authors.

Acquisition of data: KS Cheung, YC Siu, RHW Chan.

Analysis or interpretation of data: KS Cheung, LP Leung.

Drafting of the article: KS Cheung.

Critical revision for important intellectual content: All authors.

\section{Acknowledgement}

We would like to thank the staff of the following institutions: 
Hong Kong Fire Services Department, for performing prehospital electrocardiograms and providing prehospital data; Division of Cardiology, Department of Medicine, Queen Mary Hospital, for providing data on door-to-balloon and door-to-catheter time; Department of Accident and Emergency, Queen Mary Hospital, for collecting patient clinical data; Emergency Medical Unit, LKS Faculty of Medicine, the University of Hong Kong, for statistical analyses; and Zoll Medical Corporation (269 Mill Rd, Chelmsford, MA 01824-4105, US), for providing the machines, training, and technical support free of charge.

\section{Declaration}

All authors have disclosed no conflicts of interest. All authors had full access to the data, contributed to the study, approved the final version for publication, and take responsibility for its accuracy and integrity.

\section{Funding/support}

This research received no specific grant from any funding agency in the public, commercial, or not-for-profit sectors.

\section{Ethical approval}

Analysis of data from this pilot project was approved by the Institutional Review Board of the University of Hong Kong/ Hospital Authority Hong Kong West Cluster (UW17-318). Patient consent was waived.

\section{References}

1. Nagel EL, Hirshman JC, Nussenfeld SR, Rankin D, Lundblad E. Telemetry-medical command in coronary and other mobile emergency care systems. JAMA 1970;214:332-8.

2. O'Connor RE, Al Ali AS, Brady WJ, et al. Part 9: acute coronary syndromes: 2015 American Heart Association Guidelines Update for Cardiopulmonary Resuscitation and Emergency Cardiovascular Care. Circulation 2015;132:S483-500.
3. Le May MR, Davies RF, Dionne R, et al. Comparison of early mortality of paramedic-diagnosed ST-segment elevation myocardial infarction with immediate transport to a designated primary percutaneous coronary intervention center to that of similar patients transported to the nearest hospital. Am J Cardiol 2006;98:1329-33.

4. Thygesen K, Alpert JS, Jaffe AS, et al. Fourth universal definition of myocardial infarction (2018). Eur Heart J 2018 Aug 25. Epub ahead of print.

5. Anderson LL, French WJ, Peng SA, et al. Direct transfer from the referring hospitals to the catheterization laboratory to minimize reperfusion delays for primary percutaneous coronary intervention: insights from the National Cardiovascular Data Registry. Circ Cardiovasc Interv 2015;8:e002477.

6. Cockburn J, Karimi K, Hoo S, et al. Outcomes by day and night for patients bypassing the emergency department presenting with ST-segment elevation myocardial infarction identified with a pre-hospital electrocardiogram. J Interv Cardiol 2015;28:24-31.

7. Wong KL, Wong YT, Yung SY, et al. A single centre retrospective cohort study to evaluate the association between implementation of an acute myocardial infarction clinical pathway and clinical outcomes. Int J Cardiol 2015;182:82-4.

8. Hong CC, Sultana P, Wong AS, Chan KP, Pek PP, Ong ME. Prehospital delay in patients presenting with acute ST-elevation myocardial infarction. Eur J Emerg Med 2011;18:268-71.

9. Song L, Yan HB, Yang JG, et al. Factors associated with use of emergency medical service for acute myocardial infarction in Beijing [in Chinese]. Zhonghua Yi Xue Za Zhi 2010;90:834-8.

10. Mathews R, Peterson ED, Li S, et al. Use of emergency medical service transport among patients with STsegment-elevation myocardial infarction: findings from the National Cardiovascular Data Registry Acute Coronary Treatment Intervention Outcomes Network Registry-Get With The Guidelines. Circulation 2011;124:154-63. 